\title{
Antitumorigenic Effect of a High Protein Diet in Mouse Skin
}

\author{
Ka-Hee Tak and Eunjung $\mathrm{Kim}^{\dagger}$ \\ Department of Food Science and Nutrition, Catholic University of Daegu, Gyeongbuk 712-702, Korea
}

\begin{abstract}
The recent increase of colon, breast, and prostate cancer incidence in Korea has been attributed to a diet pattem change to a more Westem style, in which the foods eaten are higher in protein and fat. Whether high protein intake itself stimulates tumor cell growth and exacerbates disease status has been investigated, however, many epidemiological studies have inconsistent results between meat intake and the risk of certain cancers. These inconsistent results are partly because of the difficulty of studying the effects of just the meat intake. Other factors, such as overall meal context, could not be completely excluded in the study. To address the question of whether high protein itself is independently associated with carcinogenesis, we initiated ICR mice with $200 \mathrm{nmol}(50$ $\mu \mathrm{g})$ 7,12-dimethylbenz $[a]$ anthracene (DMBA) and fed animals either a normal diet (ND, 14\% casein) or a high protein diet (HPD, 50\% casein) for 15 weeks with 12-O-tetradecanoylphorbol-13-acetate (TPA) promotion in two-stage skin carcinogenesis protocol. There was no significant difference between ND and HPD group in food intake and body weight throughout the experiment. However, tumor multiplicity of the HPD group was decreased by $75.5 \%$ compared to that of the ND group. In addition, HPD inhibited skin hyperplasia and epidermal cell proliferation. Westem analyses with whole skin lysates showed that HPD inhibited TPA-induced Akt (S473), S6K (T389), 4E-BP1 (Thr 37/46) and Erk1/2 (Thr202/Tyr204) phosphorylation as well as COX-2 expression. Taken together, these data suggest that a high protein diet has an anticarcinogenic effect by inhibiting the TPA-induced Akt signaling pathway.
\end{abstract}

Key words: high protein diet, mouse skin cancer, Akt signaling

\section{INTRODUCTION}

Cancer has been a leading cause of death throughout the world. Various factors including genetic and environmental factors can affect cancer incidence, however, diet is one of the major causes of cancer, along with tobacco (1). Recent increase of colon, breast, and prostate cancer incidence in Korea has also been thought to result from a change in the diet to a more Western style, including high protein and high fat foods.

The effect of a high protein diet on cancer is, however, still under debate. According to a prospective investigation study with 142,251 European men, a 35 g/day increase in consumption of dairy protein was associated with a $32 \%$ increase of prostate cancer incidence (2). A pooled analysis of 13 prospective studies reported that intakes of meat (red meat, processed meat, poultry) was not associated with the risk of renal cell cancer (3). A large volume of epidemiological evidence that looked at meat as a risk factor for colorectal cancer is inconsistent between Europe and the United States, likely because of the different contexts of the meals in the different countries (4). On the other hand, a high energy and high protein diet is generally recommended to cancer patients for the efficacy of chemotherapy and for the improvement of total body health, including immune system. It cannot be excluded, however, that a high protein diet stimulates tumor cell growth and exacerbates the disease, since amino acids are well-known activator of mammalian target of rapamycin (mTOR), a central regulator of cell growth (5).

A mouse skin carcinogenesis model has been traditionally used to investigate a multistage process of malignant neoplasm development (6-10). Distinct physiological and molecular events in each process can be relatively easily detected and, moreover, skin tumor development can be seen by eye without sacrificing animals. The process is largely divided into three stages: tumor initiation, promotion, and progression. In tumor initiation stage, a single application of carcinogen such as 7,12-dimethylbenz[a] anthracene (DMBA) to mouse skin causes a mutation of an oncogene (e.g., H-ras) (11). In the tumor promotion stage, repetitive treatment of tumor promoters, such as 12-O-tetradecanoylphorbol-13-acetate (TPA) to the initiated skin leads to clonal expansion of initiated cells and results in benign epidermal tumors called papillomas (12). If the additional genetic mutations occur in the pap- 
illomas, those can be converted to malignant carcinomas in tumor progression stage.

TPA treatment of mouse skin induces various epigenetic changes, including inflammation, induction of epidermal hyperplasia, alteration of gene expression, and signal transduction (13). TPA elicits those events mainly by binding to the cysteine-rich zinc fingers in the protein kinase C (PKC) with much higher potency than an endogenous ligand, diacylglycerol $(14,15)$. Activated PKC then triggers mitogen-activated protein kinase (MAPK) cascades, which leads to the expression of genes involved in hyperproliferation and inflammation, such as cyclooxygenase-2 (COX-2) (16). Recently, a large body of evidence indicated that activation of the phosphoinositide-3-kinase (PI3K)/Akt signaling pathway plays a critical role in COX-2 expression, as well as skin tumorigenesis. TPA-induced COX-2 expression correlated well with the increased Akt activity; moreover, specific inhibition of Akt with PI3K inhibitor or expression of dominant negative Akt inhibits COX-2 expression (17).

Akt is a member of the AGC family of serine/threonine protein kinases activated by an upstream receptor kinase signaling pathway, such as insulin receptor and insulin-like growth factor I receptor. Ligand binding to the receptor activates the kinase activity of the receptor, which phosphorylates insulin receptor substrate 1 (IRS1). Activated IRS-1 recruits Src-homology-2 (SH2) domain-containing proteins, such as PI3K $(18,19)$, which produces phosphatidylinositol-3-phosphate $(\operatorname{Ptd} \operatorname{Ins}(3,4$, 5) $\left.\mathrm{P}_{3}\right)$ on the cell membrane. PtdIns $(3,4,5) \mathrm{P}_{3}$ recruits pleckstrin homology $(\mathrm{PH})$ domain-containing proteins, including phosphoinositide-dependent kinase 1 (PDK1), which phosphorylates and activates Akt (20). Upon activation, Akt leads to downstream signaling components, including mTOR, endothelial nitric oxide synthase, and forkhead transcription factors, which modulate cell proliferation and survival (21). Lu et al. (22) showed that a single topical application of diverse chemical skin tumor promoters to mouse skin rapidly activates epidermal Akt.

We studied the efficacy of a high protein diet on skin tumorigenesis and show that a high protein diet significantly decreased mouse skin tumor development by inhibiting the TPA-induced Akt signaling pathway.

\section{MATERIALS AND METHODS}

\section{Animals and diets}

Twenty female ICR mice were obtained from Orient Bio Inc. (Seongnam, Korea) at 5 weeks of age. Animals were acclimated for 1 week and divided into two groups: normal diet $(\mathrm{ND}, \mathrm{n}=10)$ and high-protein $\operatorname{diet}(\mathrm{HPD}, \mathrm{n}=$
Table 1. Composition of experimental diets ( $\mathrm{g} / \mathrm{kg}$ diet)

\begin{tabular}{lcc}
\hline \multirow{2}{*}{ Ingredients } & \multicolumn{2}{c}{ Groups } \\
\cline { 2 - 3 } & $\mathrm{ND}^{1)}$ & $\mathrm{HPD}^{2)}$ \\
\hline Corn starch & 466 & 106 \\
Dextrin & 155 & 155 \\
Casein & 140 & 500 \\
Sucrose & 100 & 100 \\
Cellulose & 50 & 50 \\
Soybean oil & 40 & 40 \\
AIN 93M mineral mix & 35 & 35 \\
AIN 93 vitamin mix & 10 & 10 \\
Choline bitartrate & 2.5 & 2.5 \\
L-Cystine & 1.8 & 1.8 \\
t-Butylhydroquinone & 0.008 & 0.008 \\
\hline Total (g) & 1000.308 & 1000.308 \\
\hline${ }^{1)}$ ND: normal diet (AIN-93M). & \multicolumn{2}{|}{} \\
${ }^{2)}$ HPD: high protein diet. & \multicolumn{2}{|}{}
\end{tabular}

10) group. At 6 weeks of age, animals were fed ad libitum either an ND (14\% casein) or HPD (50\% casein) for 17 weeks (Table 1). All animals were kept in controlled conditions of humidity ( $50 \pm 10 \%)$, light (12-hour light/dark cycle), and temperature $\left(23 \pm 2^{\circ} \mathrm{C}\right)$. Food intake was recorded daily and body weight was measured once a week.

\section{Two-stage skin carcinogenesis}

At 6 weeks of age, dorsal skins of the mice were shaved 2 days prior to tumor initiation. Initiation was accomplished by a single topical application with 200 nmol $(50 \mu \mathrm{g})$ DMBA (Sigma, St. Louis, MO, USA) under subdued light. At 2 weeks after initiation, the mice were treated with $6.5 \mathrm{nmol}(4 \mu \mathrm{g})$ of TPA (Alexis Biochemicals, San Diego, CA, USA) in $200 \mu \mathrm{L}$ of acetone twice a week for 15 weeks. The tumor incidence (number of mice bearing tumors/total number of mice) and the tumor multiplicity (number of papillomas/mouse) were manually counted and recorded weekly. Tumor size was measured with calipers at the end of experiment.

\section{Westem analysis}

Whole skin was homogenized in RIPA buffer $(0.1 \%$ SDS, $1 \%$ Triton X-100, $0.5 \%$ deoxycholate, $50 \mathrm{mM}$ Tris (pH 7.5), $150 \mathrm{mM} \mathrm{NaCl}, 50 \mathrm{mM} \mathrm{NaF}, 1 \mathrm{mM}$ EDTA, $1 \mathrm{mM}$ EGTA, $1 \mathrm{mM}$ DTT, $1 \mathrm{mM}$ PMSF, $10 \mu \mathrm{g} / \mathrm{mL}$ leupeptin, $10 \mu \mathrm{g} / \mathrm{mL}$ aprotinin). Samples were resolved by SDS-PAGE and transferred to polyvinylidene difluoride membrane. The blot was blocked with 5\% non-fat dried milk in $0.1 \%$ Tween-20-Tris-buffered saline (TTBS) and probed overnight at $4^{\circ} \mathrm{C}$ with antibody against phosphoAkt (S473), Akt, phospho-S6K (T389), S6K, phospho4EBP1 (Thr 36/46), 4EBP1, phospho-Erk1/2 (Thr 202/ Tyr 204) (Cell Signaling Technology, Danvers, USA), COX-2 (BD Biosciences, San Jose, CA, USA), and Actin (Santa Cruz biotechnology, Santa Cruz, CA, USA) at 
1:1000 dilution. After washing three times with $0.1 \%$ TTBS, the blot was then probed with horseradish peroxidase-conjugated secondary antibody (Santa Cruz biotechnology) at 1:1000 dilution for $1 \mathrm{hr}$ at room temperature. After washing three times with $0.1 \%$ TTBS, the specific bands were detected by an enhanced chemiluminescence kit (Bio Science Technology, Pohang, Korea).

\section{Histological analysis}

Twelve female ICR mice were obtained from the Orient Bio Inc. (Seongnam, Korea) at 5 weeks of age. Animals were acclimated for 1 week and divided into $\mathrm{ND}(\mathrm{n}=6)$ and HPD $(\mathrm{n}=6)$ groups. At 6 weeks of age, animals were fed ad libitum either an ND or HPD for 4 weeks. In each diet group, dorsal skin of the mice were shaved and treated with either acetone or TPA (6.5 nmol $(4 \mu \mathrm{g}) / 200 \mu \mathrm{L}$ acetone/mouse) twice a week for 2 weeks before animals were sacrificed.

For measuring the rate of epidermal cell proliferation, $100 \mathrm{mg} / \mathrm{kg}$ body weight of 5-bromo-2'-deoxyuridine (BrdU, Sigma, St. Louis, MO, USA) was injected i.p. into mice $1 \mathrm{hr}$ before sacrifice. Dorsal skin was isolated from the mice, fixed in formalin, and processed for paraffin embedding. Tissue sections were stained with hematoxylin and eosin (H\&E) and immunostained with antibodies against BrdU (BD Biosciences, San Jose, CA, USA). The number of BrdU-positive cells in the interfollicular epidermis was counted in five random tissue sections in each mouse. The labeling index was calculated as the percentage of BrdU-positive basal cells to total number of basal cells in the interfollicular epidermis.

\section{Statistical analysis}

Data were expressed as means \pm standard error (SE). Student's $t$-test was conducted using SPSS statistical packages (ver. 19) to determine the statistical differences between experimental groups. A p-value $<0.05$ was considered statistically significant.

\section{RESULTS}

\section{Body weight and food intake}

Body weight was not significantly different between ND and HPD groups throughout the experimental period (Fig. 1). Daily food intake was also similar between two groups, however, mice in HPD group tended to eat less (8.42 g vs $7.48 \mathrm{~g}$ for ND and HPD group, respectively, Table 2)

\section{Tumor multiplicity and incidence}

Tumor multiplicity was significantly decreased in HPD fed mice (Fig. 2A). At 15 weeks of tumor promotion,

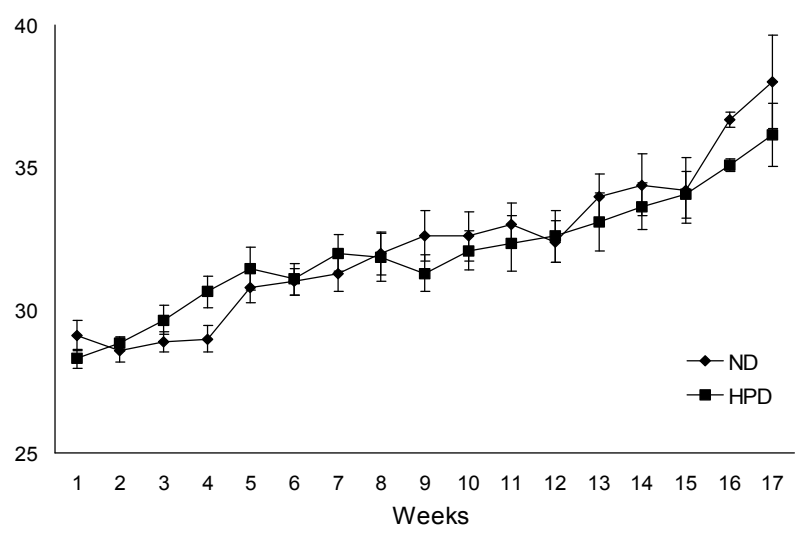

Fig. 1. Weekly changes of body weight. ICR mice were fed either ND $(n=10)$ or HPD $(n=10)$ for 17 weeks. Body weight of each mouse was recorded once a week. Each value is the mean $\pm \mathrm{SE}$.

Table 2. Daily diet intake

\begin{tabular}{lc}
\hline Group & Food intake (g/day) \\
\hline ND & $8.42 \pm 0.12^{2)}$ \\
HPD $^{1)}$ & $7.48 \pm 0.15$ \\
\hline
\end{tabular}

${ }^{1)}$ HPD: high protein diet. ${ }^{2)}$ Values are mean \pm SE.
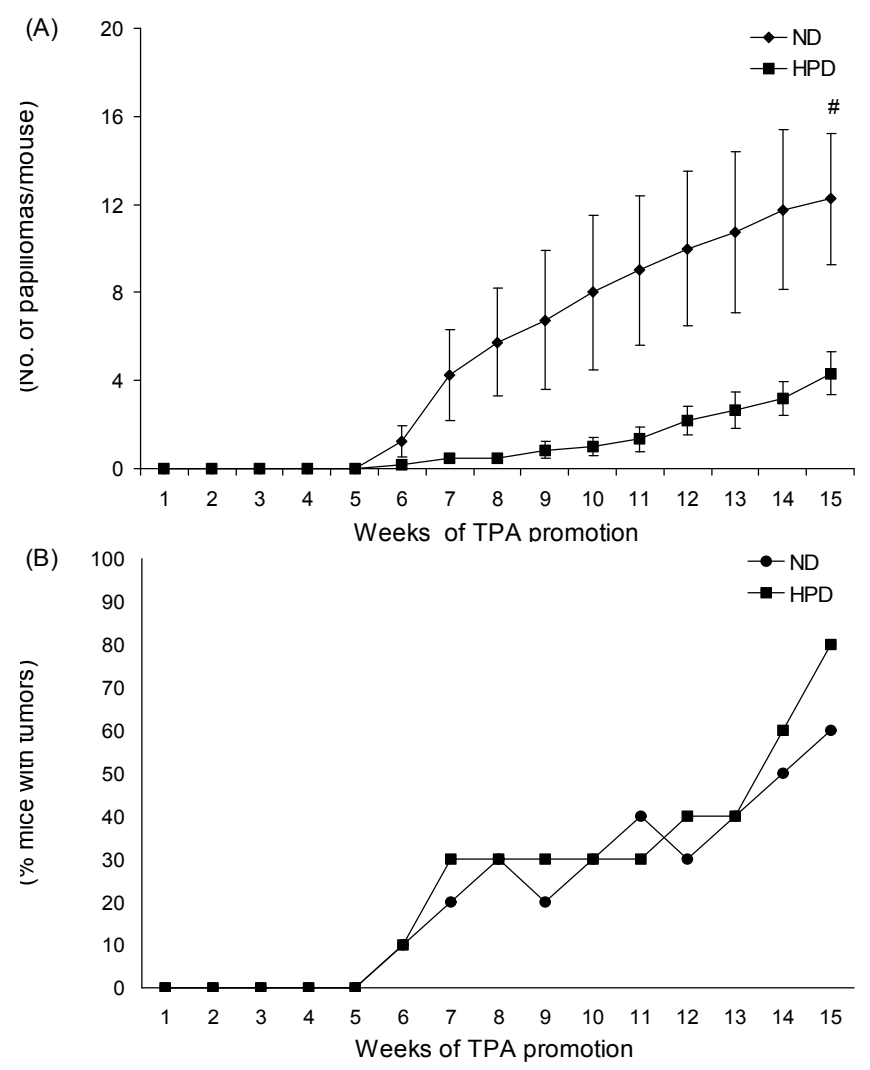

Fig. 2. Two-stage skin carcinogenesis study. Ten female mice in each ND $(n=10)$ and HPD $(n=10)$ group were initiated with $200 \mathrm{nmol}(50 \mu \mathrm{g})$ DMBA and promoted with $6.5 \mathrm{nmol}(4$ $\mu \mathrm{g})$ of TPA in $200 \mu \mathrm{L}$ of acetone twice a week for 15 weeks. (A) Tumor multiplicity (average number of papillomas/tumor bearing mouse) and (B) incidence of tumors (percentage of mice bearing tumors) were recorded weekly. Each value is the mean \pm SE. ${ }^{\#} \mathrm{p}<0.1$. 
Table 3. Tumor size

\begin{tabular}{cccc}
\hline No. of tumors & \multicolumn{2}{c}{ Tumor size $(\mathrm{cm})$} & $\begin{array}{c}\text { Total number } \\
\text { of tumors }\end{array}$ \\
\cline { 2 - 4 } Group & $<0.5$ & $0.5 \leq$ & $12.25 \pm 4.29^{*}$ \\
ND & $12.0 \pm 4.14$ & $0.25 \pm 0.25$ & $125 \pm 1.20$ \\
HPD & $4.3 \pm 1.20$ & 0 & $4.30 \pm 1.20$ \\
\hline
\end{tabular}

The size and number of tumors were measured in each diet group at the end of experiment.

Values are mean \pm SE. $\mathrm{p}<0.1$.

tumor multiplicity of the mice in HPD group was $75.5 \%$ lower than that of the mice in ND group (average 4.3 and 12.5 papillomas/mice for HPD and ND group, respectively, Table 3). However, tumor incidence was higher in the HPD group compared to the ND group at 14 and 15 weeks. At the end of the experiment, $80 \%$ and $60 \%$ of mice in HPD and ND group, respectively, developed skin papillomas (Fig. 2B). Of note is that the fluctuation of tumor incidence shown in Fig. 2B is due to regression of some small size tumors.

\section{Epidermal cell proliferation}

To identify a mechanism of reduced tumor development by HPD in mice, we performed a BrdU incorporation experiment. Animals were fed ad libitum either an ND or HPD for 4 weeks and treated with either acetone or TPA twice a week for last 2 weeks. BrdU was injected i.p. $1 \mathrm{hr}$ before the animals were sacrificed.

TPA treatment to dorsal skin caused skin hyperplasia, which indicates epidermal cell proliferation. Histological analysis showed that the epidermis of HPD fed mice was thinner than that of ND group (Fig. 3A, 3C), which became more obvious with TPA treatment (Fig. 3B, 3D). The rate of basal and TPA-induced cell proliferation in the interfollicular epidermis was also significantly reduced by HPD (Fig. 3E).

Western analysis showed that TPA treatment to mouse skin increased phosphorylation of Akt (S473) and of its downstream signaling components such as S6K (T389) and 4E-BP1 (Thr37/46) (Fig. 4A 4D). TPA-induced activation of Erk1/2 (Thr 202/Tyr 204) and increased expression of COX-2 was also observed (Fig. 4E, 4F). Interestingly, however, HPD feeding abolished TPA-induced responses of these proteins.

\section{DISCUSSION}

Meat consumption has been a focus of interest as a risk factor for several cancers (e.g., colon, breast, and prostate cancer) in many epidemiological studies (23-26). The results, however, showed that there is no clear association or scientific consensus between red or processed meat intake and the risk of these cancers. This lack of consensus is partly due to food intake other than meat, such as fruit and vegetables, alcohol consumption, and other factors, such as physical activity, that could not be completely excluded in the studies (4). In addition, if meat intake does increase the risk of cancer, this risk may not be a function of meat, per se, because meat also contains fat and/or certain carcinogens that can be generated through various cooking and processing methods $(27,28)$. In this study, we addressed the question of
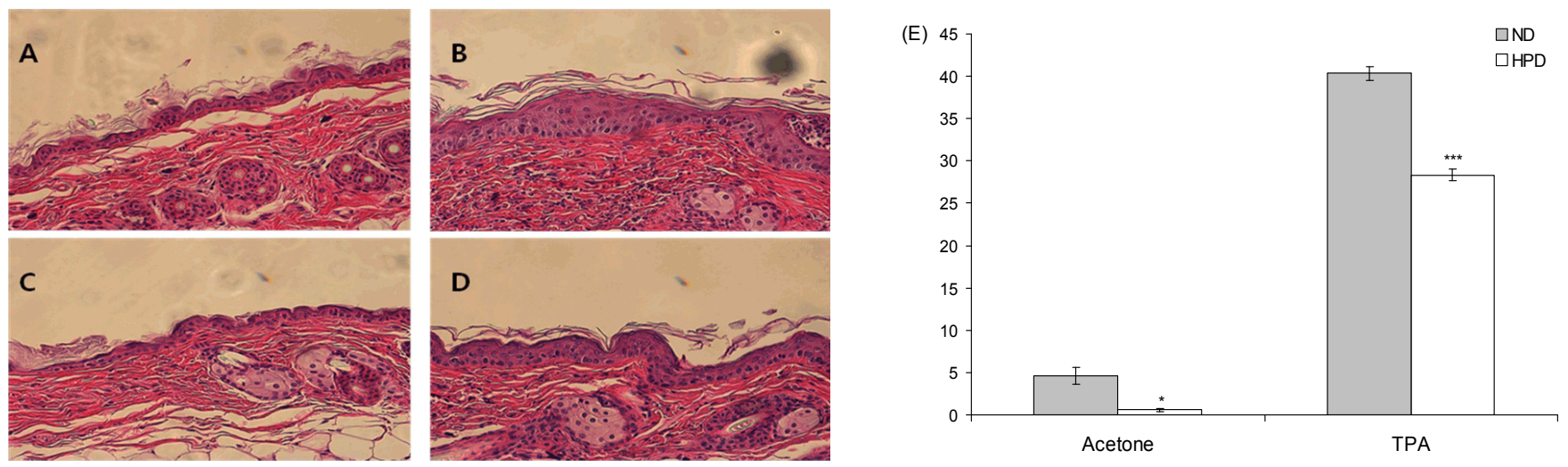

Fig. 3. Epidermal cell proliferation. Twelve female ICR mice were fed ad libitum either an ND (N=6) or HPD (N=6) for 4 weeks. In each diet group, dorsal skin of the mice was shaved and treated with either acetone or TPA $(6.5 \mathrm{nmol}(4 \mu \mathrm{g}) / 200$ $\mu \mathrm{L}$ acetone/mouse) twice a week for 2 weeks before the animals were sacrificed. For measuring the rate of epidermal cell proliferation, $100 \mathrm{mg} / \mathrm{kg}$ body weight of BrdU was injected i.p. into mice $1 \mathrm{hr}$ before sacrifice. Dorsal skin was isolated from mice, fixed in formalin, and processed for paraffin embedding. Tissue sections were stained with hematoxylin and eosin (H\&E) and immunostained with antibodies against BrdU. All sections were photographed at $\times 200$. Tissue sections of (A) acetone-treated skin of mice in ND group, (B) TPA-treated skin of mice in ND group, (C) acetone-treated skin of mice in HPD group, (D) TPA-treated skin of mice in HPD group. Data are representative of at least three independent tissues. (E) Labeling index of acetone or TPA-treated mouse skin in each diet group. The index represents the percentage of BrdU-positive cells relative to the total number of basal cells in the interfollicular epidermis. Each value is the mean $\pm \mathrm{SE}$. of labeling indices from three mice/group. ${ }^{*} \mathrm{p}<0.05,{ }^{* * *} \mathrm{p}<0.001$. 
(A)

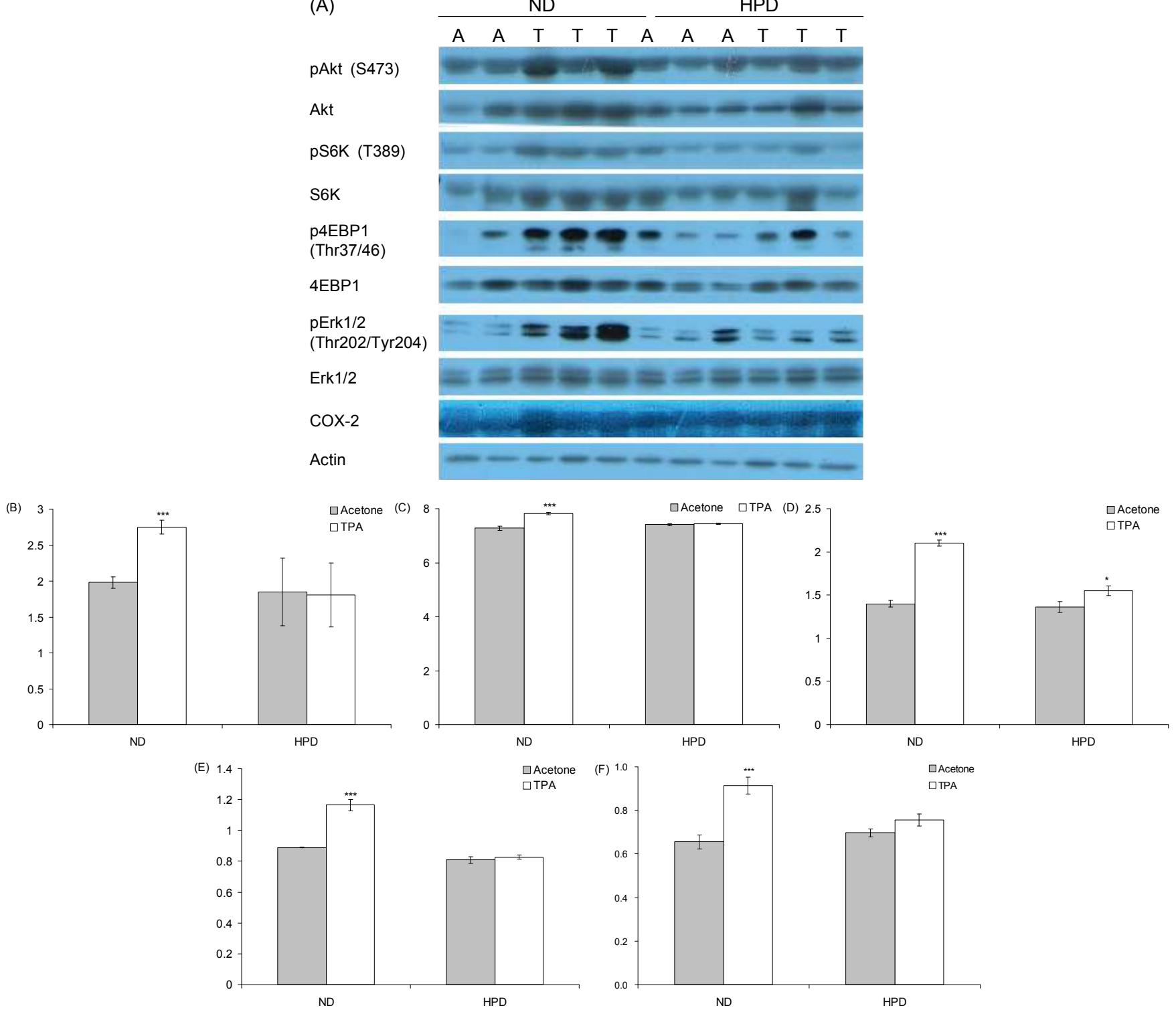

Fig. 4. Effect of HPD on Akt signaling pathway and COX-2 expression. Twelve female ICR mice were fed ad libitum either an ND $(\mathrm{N}=6)$ or HPD $(\mathrm{N}=6)$ for 4 weeks. In each diet group, dorsal skin of the mice were shaved and treated with either acetone or TPA $(6.5 \mathrm{nmol}(4 \mu \mathrm{g}) / 200 \mu \mathrm{L}$ acetone/mouse) twice a week for 2 weeks before animals were sacrificed. (A) Whole skin lysates were subjected to western analysis. Phosphorylation and protein level were determined by immunostaining with the appropriate antibodies. A: acetone, T: TPA. (B) (F) Quantification of western analysis. Signals of phosphorylated protein and COX-2 were normalized to total protein levels of each protein and actin, respectively. The data shown are representative of triplicate experiments and each value is the mean $\pm \mathrm{SE} .{ }^{*} \mathrm{p}<0.05,{ }^{* * *} \mathrm{p}<0.001$.

whether high protein itself is independently associated with tumor development and here we provide strong evidence that the increase of casein (as a source of animal protein) from $14 \%(\mathrm{ND})$ to $50 \%$ (HPD) to an otherwise isocaloric experimental diet does, in fact, significantly inhibit mouse skin carcinogenesis.

Ho et al. (29) recently found that carbohydrate (CHO) reduction (from $55.2 \%$ to $10.6 \%$ or $15.6 \%$ ) and protein increase (from $23.2 \%$ to 58.2 or $63.5 \%$ ) in the energy composition of diet inhibited growth of SCCVII xenograft tumors and the tumor incidence in NOP mice, which are spontaneous mouse models of breast cancer. Rose et al. (30) showed that dietary glycine supplementation ( $5 \%$ glycine and $15 \%$ casein) inhibited growth of tumors arising from B16 melanoma cell implanted C57BL/6 mice compared to that of control diet $(20 \%$ casein) fed mice. On the other hand, although 1 or 2 papillomas developed in some of the mice, tumor incidence became higher at 14 and 15 weeks of TPA promotion in the HPD group compared to that of the ND group. It has been shown that a high-fat/high-protein diet $(30 \%$ protein and $30 \%$ fat) promoted the occurrence 
of DMBA-induced pancreatic ductal adenocarcinomas during a 9-month experimental period in rats (31). Nevertheless, since the decrease of tumor incidence is another critical aspect of antitumorigenic properties, it is absolutely needed to investigate more thoroughly the effect of a high protein diet in the occurrence of mouse skin cancer.

To investigate the mechanism by which HPD inhibits skin tumorigenesis, we analyzed epidermal hyperplasia and the rate of epidermal cell proliferation. The result showed that HPD suppressed TPA-induced skin hyperplasia as well as both basal- and TPA-induced epidermal cell proliferation. Recently, it has been reported that Akt signaling plays an important role in both skin tumor promotion and progression stages $(22,32)$. TPA treatment led to activation of Akt and its downstream effectors in cultured primary keratinocytes as well as in mouse skin (22). In addition, overexpression of Akt transformed keratinocytes (32) and targeted Akt overexpression in the basal layer of stratified epithelia using the bovine keratin K5 promoter in mice developed spontaneous epithelial tumors in multiple organs (33). In our study, multiple TPA treatment also increased phosphorylation of Akt and its downstream signaling components such as $\mathrm{S} 6 \mathrm{~K}$ and 4E-BP1 in mouse skin of ND group. HPD feeding abolished this TPA induced Akt signaling activation as well.

It appears that the protein levels of Akt, S6K, and 4E-BP1 are also a little bit decreased in both acetoneand TPA-treated skin of the HPD group compared to that of ND group. This can be partly because of negative feedback inhibition of mTOR signaling pathway. mTOR is a serine/threonine protein kinase that exists in two distinct protein complexes, mTOR complex 1 (mTORC1) and mTOR complex 2 (mTORC2) (34-36). mTORC1 regulates cell growth and size by stimulating protein synthesis and by inhibiting autophagy (37-39). The most wellknown substrates of mTORC1 are S6K and 4EBP1, which are involved in the ribosome biogenesis and translation initiation, respectively (40). The activity of mTORC1 is tightly controlled by a wide range of signals such as growth factors, insulin, cellular energy levels, and amino acids (41-43). Indeed, amino acids are one of the most important regulators of mTORC1 activity (reviewed in (5)); in their absence, growth factors and insulin cannot activate mTORC1. mTORC1 signaling pathway is closely associated with the PI3K signaling pathway, which is often highly activated in various cancer. Phosphorylated S6K, however, inhibits insulin signaling pathway by negative feedback inhibition. It directly phosphorylates insulin receptor substrate-1 (IRS-1) which leads into degradation of IRS1 (44). In fact, in C50 murine epidermal keratinocytes, amino acid starvation completely inhibited S6K phosphorylation, whereas amino acid stimulation restored S6K phosphorylation. Akt phosphorylation was, however, inversely correlated with S6K phosphorylation (data not shown). Since we used whole skin lysates, which contain various cell types, for Western analysis, we could not see clearly this phenomenon. However, we could not exclude a possibility that, although prolonged HPD feeding initially activated mTORC1 signaling, it later suppressed Akt signaling by negative feedback inhibition and consequently inhibited skin cancer development. Checkley et al. (45) recently reported that topical treatment of rapamycin, an mTORC1 inhibitor, significantly inhibited TPA-induced epidermal hyperproliferation and hyperplasia . Intraperitoneal injections of CCI-779, another mTORC1 inhibitor, to $\mathrm{C} 3 \mathrm{H} / \mathrm{HeN}$ mice after SCCVII tumor implantation also resulted in the additive effect of $10 \%$ CHO diet in reducing tumor growth (29).

On the other hand, HPD feeding decreased TPA-induced Erk1/2 activation as well as COX-2 expression. It has been shown that COX-2 gene expression is regulated by multiple signal transduction kinases such as Erk, p38, JNK, and Akt, which phosphorylate transcription factors binding to the COX-2 promoter and result in the increase of gene expression (17,46-48). A large body of evidence has shown that specific inhibition of Akt signal transduction inhibits TPA-induced COX-2 expression $(17,49,50)$. Segrelles and colleagues studied the relevance of the Akt and Erk pathways in the different stages of mouse skin tumors. Akt activity was increased throughout the entire mouse skin carcinogenesis, whereas Erk activity was not increased by TPA treatment in skin, but was significantly increased only in late papillomas (at least 20 weeks after initiation) and in squamous cell carcinomas. From this result, they proposed that Akt activity is a more primary event compared to the activity of Erk in the carcinogenesis process (32). A discrepancy between their results and ours regarding TPA-induced Erk $1 / 2$ activity is probably due to different experimental conditions, such as different mouse strain and analytical method (in vitro kinase assay vs. Western analysis).

In summary, our results demonstrate that an increase of dietary protein intake in a two-stage skin carcinogenesis protocol significantly inhibited skin tumor multiplicity. It also decreased TPA-induced epidermal hyperplasia and cell proliferation. This antitumorigenic role of HPD appears to come from its blockade of TPAinduced activation of Akt signal transduction and COX-2 expression. Considering that the effect of HPD on human cancer is not yet conclusive, more detailed mechanistic 
studies, as well as the efficacy of HPD in other cancer types, will need to be further investigated.

\section{ACKNOWLEDGEMENT}

This work was supported by the National Research Foundation of Korea (NRF) grant funded by the Korea government (MEST) No. 2010-0012980.

\section{REFERENCES}

1. Doll R, Peto R. 1981. The causes of cancer: quantitative estimates of avoidable risks of cancer in the United States today. J Natl Cancer Inst 66: 1191-1308.

2. Allen NE, Key TJ, Appleby PN, Travis RC, Roddam AW, Tjønneland A, Johnsen NF, Overvad K, Linseisen J, Rohrmann S, Boeing H, Pischon T, Bueno-de-Mesquita HB, Kiemeney L, Tagliabue G, Palli D, Vineis P, Tumino R, Trichopoulou A, Kassapa C, Trichopoulos D, Ardanaz E, Larrañaga N, Tormo MJ, González CA, Quirós JR, Sánchez MJ, Bingham S, Khaw KT, Manjer J, Berglund G, Stattin P, Hallmans G, Slimani N, Ferrari P, Rinaldi S, Riboli E. 2008. Animal foods, protein, calcium and prostate cancer risk: the European Prospective Investigation into Cancer and Nutrition. Br J Cancer 98: 1574-1581.

3. Lee JE, Spiegelman D, Hunter DJ, Albanes D, Bernstein L, van den Brandt PA, Buring JE, Cho E, English DR, Freudenheim JL, Giles GG, Graham S, Horn-Ross PL, Håkansson N, Leitzmann MF, Männistö S, McCullough ML, Miller AB, Parker AS, Rohan TE, Schatzkin A, Schouten LJ, Sweeney C, Willett WC, Wolk A, Zhang SM, Smith-Warner SA. 2008. Fat, protein, and meat consumption and renal cell cancer risk: a pooled analysis of 13 prospective studies. J Natl Cancer Inst 100: 1695-1706.

4. Hill M. 2002. Meat, cancer and dietary advice to the public. Eur J Clin Nutr 56: S36-S41.

5. Kim E. 2009. Mechanisms of amino acid sensing in mTOR signaling pathway. Nutr Res Prac 3: 64-71.

6. Slaga TJ, Fischer SM, Weeks CE, Klein-Szanto AJ, Reiners J. 1982. Studies on the mechanisms involved in multistage carcinogenesis in mouse skin. J Cell Biochem 18: 99-119.

7. Slaga TJ, Fischer SM, Nelson K, Gleason GL. 1980. Studies on the mechanism of skin tumor promotion: evidence for several stages in promotion. Proc Natl Acad Sci USA 77: 3659-3663.

8. DiGiovanni J. 1992. Multistage carcinogenesis in mouse skin. Pharmacol Ther 54: 63-128.

9. Slaga TJ, Klein-Szanto AJ, Fischer SM, Weeks CE, Nelson K, Major S. 1980. Studies on mechanism of action of anti-tumor-promoting agents: their specificity in two-stage promotion. Proc Natl Acad Sci USA 77: 2251-2254.

10. Boutwell RK, Verma AK, Ashendel CL, Astrup E. 1982. Mouse skin: a useful model system for studying the mechanism of chemical carcinogenesis. Carcinog Compr Surv 7: $1-12$.

11. Brown K, Buchmann A, Balmain A. 1990. Carcinogen-induced mutations in the mouse c-Ha-ras gene provide evidence of multiple pathways for tumor progression. Proc Natl Acad Sci USA 87: 538-542.

12. Slaga TJ. 1983. Overview of tumor promotion in animals. Environ Health Persp 50: 3-14.

13. Winberg LD, Budunova IV, Warren BS, Lyer RP, Slaga
TJ. 1995. Mechanisms of skin tumor promotion and progression. CRC Press, Inc., Boca Raton, FL, USA. p 113120.

14. Niedel JE, Kuhn LJ, Vandenbark GR. 1983. Phorbol diester receptor copurifies with protein kinase C. Proc Natl Acad Sci USA 80: 36-40.

15. Castagna M, Takai Y, Kaibuchi K, Sano K, Kikkawa U, Nishizuka Y. 1982. Direct activation of calcium-activated, phospholipid-dependent protein kinase by tumor-promoting phorbol esters. J Biol Chem 257: 7847-7851.

16. Marks F, Furstenberger G. 2000. Cancer chemoprevention through interruption of multistage carcinogenesis. The lessons learnt by comparing mouse skin carcinogenesis and human large bowel cancer. Eur J Cancer 36: 314-329.

17. Tang Q, Gonzales M, Inoue H, Bowden GT. 2001. Roles of Akt and glycogen synthase kinase 3beta in the ultraviolet $\mathrm{B}$ induction of cyclooxygenase- 2 transcription in human keratinocytes. Cancer Res 61: 4329-4332.

18. Stephens L, Anderson K, Stokoe D, Erdjument-Bromage H, Painter GF, Holmes AB, Gaffney PR, Reese CB, McCormick F, Tempst P, Coadwell J, Hawkins PT. 1998. Protein kinase B kinases that mediate phosphatidylinositol 3,4,5-trisphosphate-dependent activation of protein kinase B. Science 279: 710-714.

19. Chan TO, Rittenhouse SE, Tsichlis PN. 1999. AKT/PKB and other D3 phosphoinositide-regulated kinases: kinase activation by phosphoinositide-dependent phosphorylation. Annu Rev Biochem 68: 965-1014.

20. Kim E. 2010. Insulin resistance at the crossroads of metabolic syndrome: systemic analysis using microarrays. Biotechnol J 5: 919-929.

21. Testa JR, Tsichlis PN. 2005. AKT signaling in normal and malignant cells. Oncogene 24: 7391-7393.

22. Lu J, Rho O, Wilker E, Beltran L, Digiovanni J. 2007. Activation of epidermal akt by diverse mouse skin tumor promoters. Mol Cancer Res 5: 1342-1352.

23. Alexander DD, Cushing CA. 2011. Red meat and colorectal cancer: a critical summary of prospective epidemiologic studies. Obes Rev 12: e472-e493.

24. Alexander DD, Mink PJ, Cushing CA, Sceurman B. 2010. A review and meta-analysis of prospective studies of red and processed meat intake and prostate cancer. Nutr $J$ 9: 50 .

25. Alexander DD, Morimoto LM, Mink PJ, Cushing CA. 2010. A review and meta-analysis of red and processed meat consumption and breast cancer. Nutr Res Rev 23: 349-365.

26. McAfee AJ, McSorley EM, Cuskelly GJ, Moss BW, Wallace JM, Bonham MP, Fearon AM. 2010. Red meat consumption: an overview of the risks and benefits. Meat Sci 84: 1-13.

27. Ferguson LR. 2010. Meat and cancer. Meat Sci 84: 308313.

28. Santarelli RL, Pierre F, Corpet DE. 2008. Processed meat and colorectal cancer: a review of epidemiologic and experimental evidence. Nutr Cancer 60: 131-144.

29. Ho VW, Leung K, Hsu A, Luk B, Lai J, Shen SY, Minchinton AI, Waterhouse D, Bally MB, Lin W, Nelson BH, Sly LM, Krystal G. 2011. A low carbohydrate, high protein diet slows tumor growth and prevents cancer initiation. Cancer Res 71: 4484-4493.

30. Rose ML, Madren J, Bunzendahl H, Thurman RG. 1999. Dietary glycine inhibits the growth of B16 melanoma tumors in mice. Carcinogenesis 20: 793-798. 
31. Z'graggen K, Warshaw, AL, Werner J, Graeme-Cook F, Jimenez RE, Fernández-del Castillo C. 2001. Promoting effect of a high-fat/high-protein diet in DMBA-induced ductal pancreatic cancer in rats. Ann Surg 233: 688-695.

32. Segrelles C, Ruiz S, Perez P, Murga C, Santos M, Budunova IV, Martinez J, Larcher F, Slaga TJ, Gutkind JS, Jorcano JL, Paramio JM. 2002. Functional roles of Akt signaling in mouse skin tumorigenesis. Oncogene 21: 53-64.

33. Segrelles C, Lu J, Hammann B, Santos M, Moral M, Cascallana JL, Lara MF, Rho O, Carbajal S, Traag J, Beltran L, Martinez-Cruz AB, Garcia-Escudero R, Lorz C, Ruiz S, Bravo A, Paramio JM, DiGiovanni J. 2007. Deregulated activity of Akt in epithelial basal cells induces spontaneous tumors and heightened sensitivity to skin carcinogenesis. Cancer Res 67: 10879-10888.

34. Hara K, Maruki Y, Long X, Yoshino K, Oshino N, Hidayat S, Tokunaga C, Avruch J, Yonezawa K. 2002. Raptor, a binding partner of target of rapamycin (TOR), mediates TOR action. Cell 110: 177-189.

35. Kim DH, Sarbassov DD, Ali SM, King JE, Latek RR, Erdjument-Bromage H, Tempst P, Sabatini DM. 2002. mTOR interacts with raptor to form a nutrient-sensitive complex that signals to the cell growth machinery. Cell 110: $163-175$.

36. Sarbassov DD, Ali SM, Kim DH, Guertin DA, Latek RR, Erdjument-Bromage H, Tempst P, Sabatini DM. 2004. Rictor, a novel binding partner of mTOR, defines a rapamycin-insensitive and raptor-independent pathway that regulates the cytoskeleton. Curr Biol 14: 1296-1302.

37. Fingar DC, Salama S, Tsou C, Harlow E, Blenis J. 2002. Mammalian cell size is controlled by mTOR and its downstream targets S6K1 and 4EBP1/eIF4E. Genes Dev 16: 1472-1487.

38. Lee $\mathrm{CH}$, Inoki K, Guan KL. 2007. mTOR pathway as a target in tissue hypertrophy. Annu Rev Pharmacol Toxicol 47: 443-467.

39. Kim J, Kundu M, Viollet B, Guan KL. 2011. AMPK and mTOR regulate autophagy through direct phosphorylation of Ulk1. Nat Cell Biol 13: 132-141.

40. Inoki K, Ouyang H, Li Y, Guan KL. 2005. Signaling by target of rapamycin proteins in cell growth control. Microbiol Mol Biol Rev 69: 79-100.

41. Yang Q, Guan KL. 2007. Expanding mTOR signaling. Cell Res 17: 666-681.

42. Corradetti MN, Guan KL. 2006. Upstream of the mammalian target of rapamycin: do all roads pass through mTOR? Oncogene 25: 6347-6360.

43. Laplante M, Sabatini DM. 2009. mTOR signaling at a glance. J Cell Sci 122: 3589-3594.

44. Kim J, Guan KL. 2011. Amino acid signaling in TOR activation. Ann Rev Biochem 80: 1001-1032.

45. Checkley L, Rho O, Moore T, Hursting S, DiGiovanni J. 2011. Rapamycin is a potent inhibitor of skin tumor promotion by 12-o-tetradecanoylphorbol-13-acetate. Cancer Prev Res 4: 1011-1020.

46. Hunot S, Vila M, Teismann P, Davis RJ, Hirsch EC, Przedborski S, Rakic P, Flavell RA. 2004. JNK-mediated induction of cyclooxygenase 2 is required for neurodegeneration in a mouse model of Parkinson's disease. Proc Natl Acad Sci USA 101: 665-670.

47. Guan Z, Buckman SY, Pentland AP, Templeton DJ, Morrison AR. 1998. Induction of cyclooxygenase-2 by the activated MEKK1 $\rightarrow$ SEK1/MKK4 $\rightarrow$ p38 mitogen-activated protein kinase pathway. J Biol Chem 273: 12901- 12908.

48. Chen W, Tang Q, Gonzales MS, Bowden GT. 2001. Role of p38 MAP kinases and ERK in mediating ultraviolet-B induced cyclooxygenase- 2 gene expression in human keratinocytes. Oncogene 20: 3921-3926.

49. Jang BC, Kim DH, Park JW, Kwon TK, Kim SP, Song DK, Park JG, Bae JH, Mun KC, Baek WK, Suh MH, Hla T, Suh SI. 2004. Induction of cyclooxygenase-2 in macrophages by catalase: role of NF-kappaB and PI3K signaling pathways. Biochem Biophys Res Commun 316: 398-406.

50. Van Dross RT, Hong X, Pelling JC. 2005. Inhibition of TPA-induced cyclooxygenase-2 (COX-2) expression by apigenin through downregulation of Akt signal transduction in human keratinocytes. Mol Carcinogen 44: 8391.

(Received August 29, 2011; Accepted October 10, 2011) 